\title{
Postural electrocardiographic abnormalities
}

B.M. Rahel, H.W.M. Plokker, C.A. Ascoop

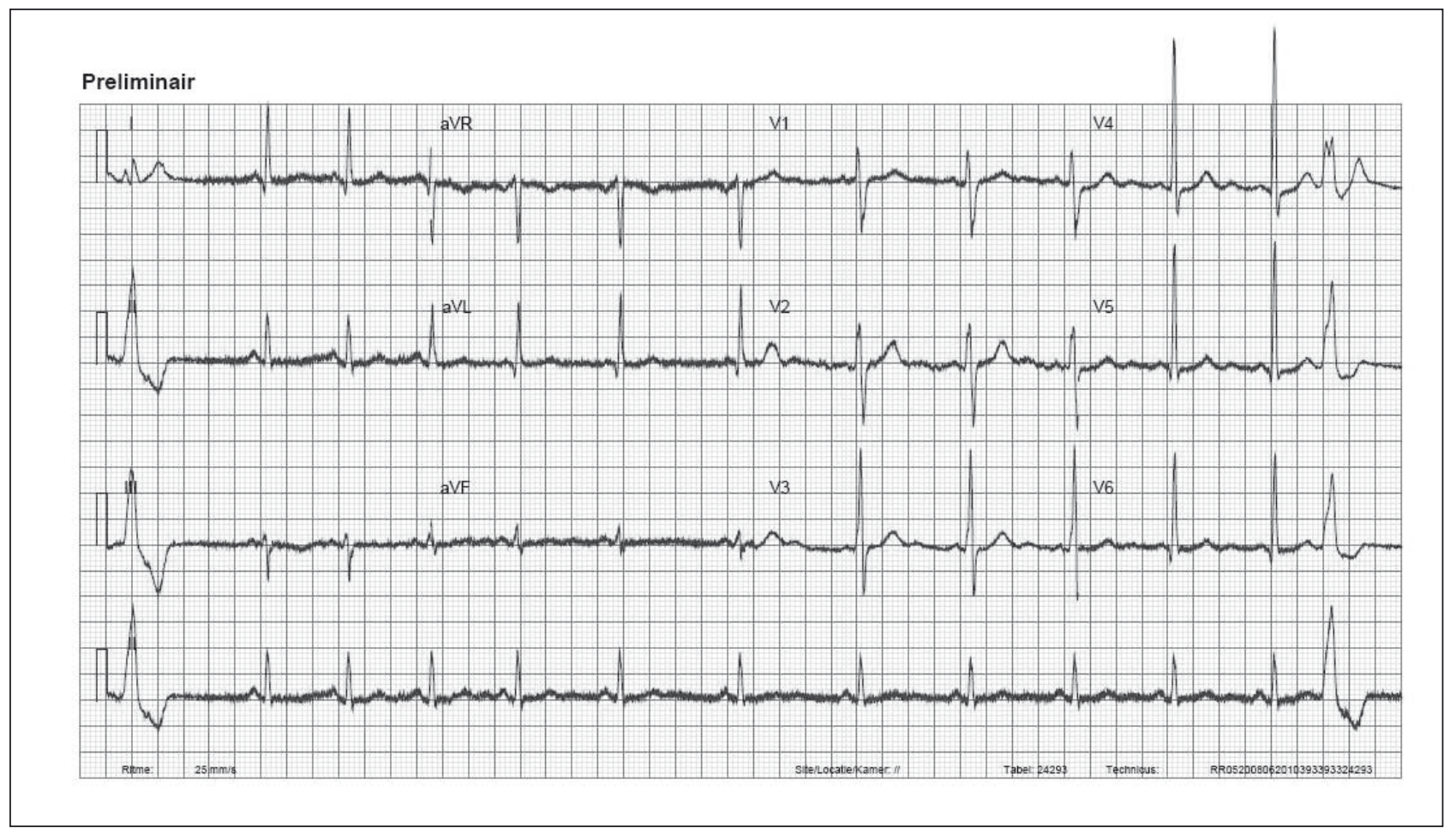

Figure 1. Electrocardiogram four days before stress testing.

B.M. Rahel

VieCuri Medisch Centrum for Noord-Limburg, Venlo, the Netherlands

\section{H.W.M. Plokker}

St. Antonius Hospital, Nieuwegein, the Netherlands

C.A.P.L. Ascoop

Retired cardiologist, Gezichtslaan 58, 3723 GG Bilthoven,

the Netherlands

Correspondence to: B.M. Rahel

VieCuri Medisch Centrum for Noord-Limburg, PO Box 1926,

5900 BX Venlo, the Netherlands

E-mail: brahel@viecuri.nl
False-positive stress testing is a common problem in daily practice. We present a young male patient with pseudo-ischaemic ST-segment changes due to upright position. (Neth Heart J 2010;18:99-102.)

Keywords: Electrocardiography; Exercise Test; Posture 


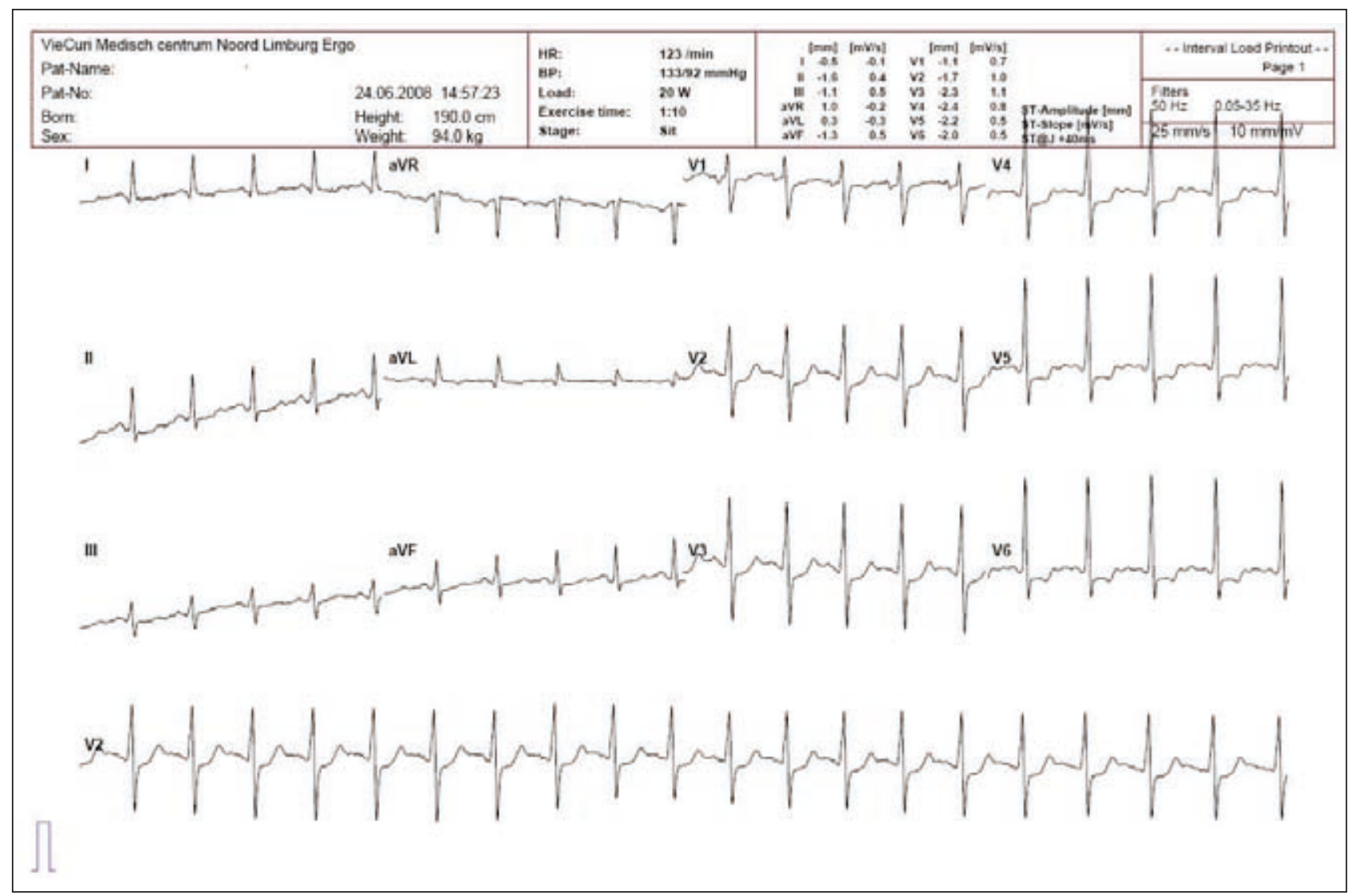

Figure 2. Electrocardiogram immediately before stress testing, upright position.

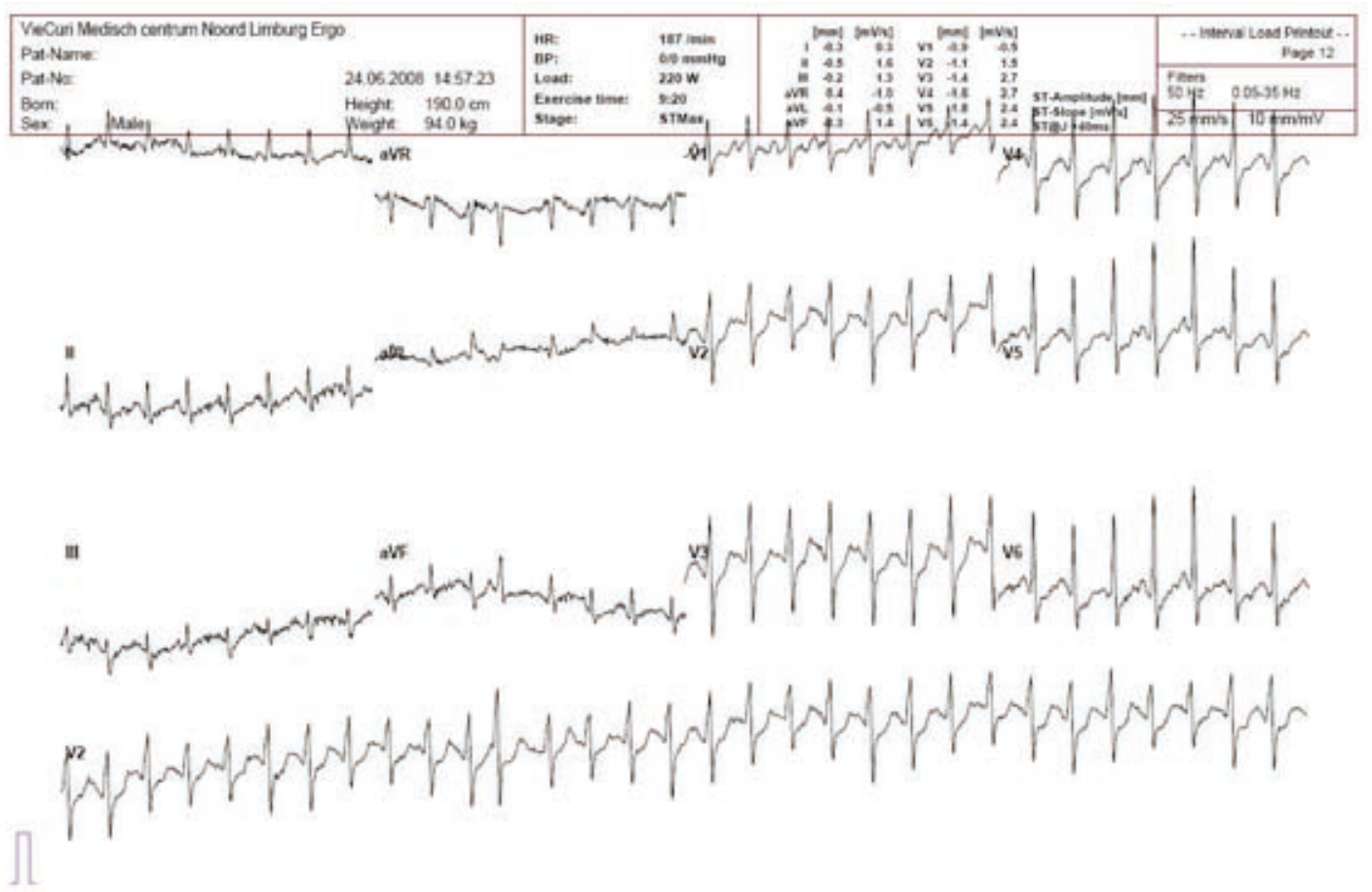

Figure 3. Electrocardiogram during maximal stress testing, 220 Watt. 


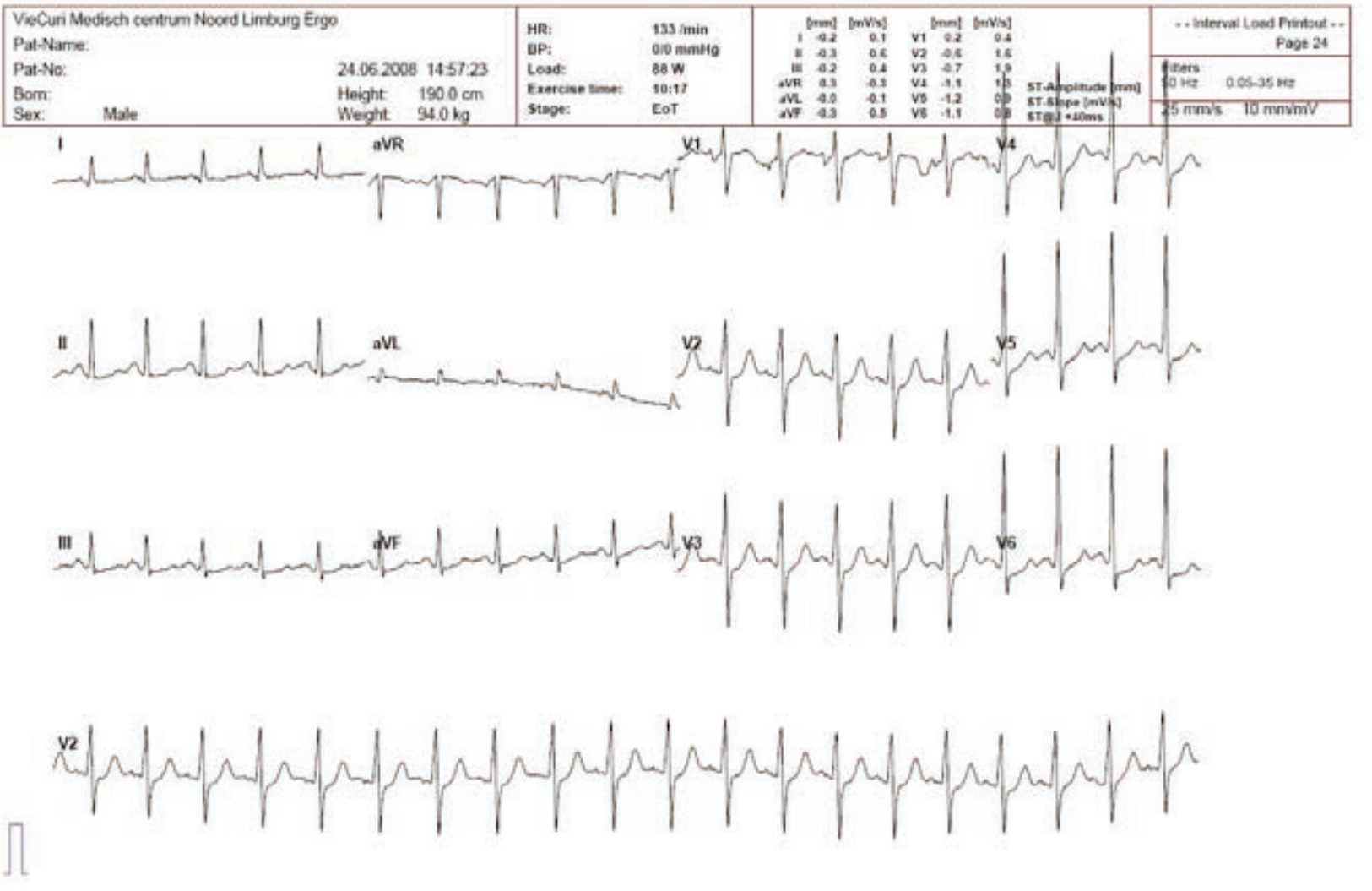

Figure 4. Electrocardiogram during recovery.

A previously healthy 37-year-old male was referred to our outpatient clinic with a history of palpitations. At physical examination no abnormalities could be detected. The electrocardiogram (ECG) and echocardiographic findings were normal. Ambulatory Holter monitoring for 24 hours showed a sinus rhythm with premature ventricular beats. The ECG at rest in the upright position immediately before stress testing showed asymptomatic 'ischaemic' ST-segment abnormalities most pronounced in the precordial leads. These ST changes became less abnormal during exercise (figures 1 to 4 ). Chest discomfort did not occur during the ST-segment shift and the patient showed a normal exercise capacity.

During dobutamine gated SPECT imaging no signs of myocardial ischaemia were found. Cardiac CT showed a calcium score of 0 and a normal coronary anatomy. A diagnosis of postural ECG changes was made. The palpitations were successfully treated with $\beta$-blockade.

\section{Discussion}

Electrocardiographic changes relative to posture were first described by Gottlieb Friesinger. ${ }^{1} \mathrm{He}$ used the term vasoregulatory abnormalities because he attributed the ECG changes to an abnormal autonomic response. Patients presenting with postural ECG changes often have atypical chest pain, a normal coronary angiogram and a normal exercise performance. There is no reason for restriction in their daily work and the prognosis is good. ST changes due to vasoregulatory abnormalities resemble ischaemic ST changes, but as opposed to ischaemic ST changes they have a tendency to normalise during exercise. In clinical practice, the principal task of exercise electrocardiography is to detect myocardial ischaemia. For this purpose we need a high predictive value of a positive test, based on a high specificity of the test. Choosing for a high specificity of the exercise ECG makes it necessary to start with a normal baseline of the repolarisation wave at rest in an upright position. 
Besides ST changes due to vasoregulatory abnormalities, there are other situations due to abnormal autonomic response which result in an abnormal baseline ST-T segment such as hyperventilation and the neurocirculatory asthenia syndrome..$^{2-5}$ These exercise ECGs must be classified as abnormal, but not as positive or negative as to the presence of myocardial ischaemia.

\section{References}

I Friesinger GC, Biern RO, Likar I, Mason RE. Exercise electrocardiography and vasoregulatory abnormalities. Am J Cardiol. 1972;30:733-40.

2 Ardissino D, De Servi S, Barberis P, Demicheli G, Falcone C, Ochan M, et al. Significance of hyperventilation-induced ST segment depression in patients with coronary artery disease. J Am Coll Cardiol. 1989;13:804-10.

3 Tavel ME. Hyperventilation syndrome-hiding behind pseudonyms. Chest. 1990;97:1285-88.

4 Oglesby P. Da Costa's syndrome or neurocirculatory asthenia. Br Heart J .1987;58:306-15.

5 Khanna KP, Balasubramian V, Dham SK, Rai K, Hoon RS. Effect of positive acceleration $(+\mathrm{gz})$ on electrocardiogram of subject with vasoregulatory abnormality. Br Heart J. 1977;39:317-22. 